\title{
miR-452-5p and miR-215-5p expression levels in colorectal cancer tissues and their relationship with clinicopathological features
}

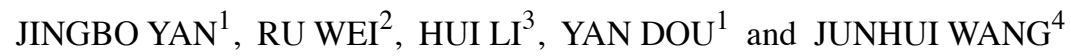 \\ ${ }^{1}$ Department of Pathology, Xingtai People's Hospital, Xingtai, Hebei 054031; \\ ${ }^{2}$ Department of Microbiology and Immunology, Xingtai Medical College, Xingtai, Hebei 054000; \\ ${ }^{3}$ Department of Surgery; ${ }^{4}$ Medical Records Room, Xingtai People's Hospital, Xingtai, Hebei 054031, P.R. China
}

Received May 16, 2019; Accepted May 27, 2020

DOI: $10.3892 / \mathrm{ol} .2020 .11845$

\begin{abstract}
The aim of the study was to investigate the expression levels of miR-452-5p and miR-215-5p in colorectal cancer tissues and their relationship with clinicopathological features. A total of 50 specimens of cancerous and adjacent normal tissues were collected from patients with colorectal cancer who underwent surgical resection at the Xingtai People's Hospital from March 2012 to February 2014. All specimens were confirmed by the Department of Pathology. Reverse transcription-quantitative polymerase chain reaction (RT-qPCR) was used to measure the expression levels of miR-452-5p and miR-215-5p in cancerous and adjacent normal tissues. Moreover, the relationship of the expression levels of miR-452-5p and miR-215-5p with the clinicopathological features of patients with colorectal cancer was explored. The expression levels of both miR-452-5p and miR-215-5p in colorectal cancer tissues were significantly lower than those in adjacent normal tissues $(\mathrm{P}<0.05)$. miR-452-5p expression was related to tumor-node-metastasis (TNM) staging and differentiation degree in colorectal cancer tissues, and the expression of miR-215-5p was associated with TNM staging, lymph node metastasis and infiltration depth $(\mathrm{P}<0.05)$. The 5-year overall survival (OS) rate in the miR-452-5p high-expression group was significantly higher than that in the low-expression group $(\mathrm{P}<0.05)$. The 5-year OS rates in the miR-215-5p high- and low-expression groups were $53.57 \%(15 / 28)$ and $40.91 \%(9 / 22)$, respectively, indicating that the 5 -year OS rate in the miR-215-5p high-expression group was significantly higher than that in the low-expression group. Cox proportional hazards regression model showed that TNM staging, lymph node metastasis, as well as miR-452-5p and miR-215-5p expression levels were independent risk factors affecting colorectal cancer prognosis
\end{abstract}

Correspondence to: Dr Jingbo Yan, Department of Pathology, Xingtai People's Hospital, 16 Hongxing Street, Qiaodong, Xingtai, Hebei 054031, P.R. China

E-mail: jjdx55@163.com; yanjingbo2012@163.com

Key words: colorectal cancer, miR-452-5p, miR-215-5p, clinicopathological features
$(\mathrm{P}<0.05)$, whereas the differentiation degree and infiltration depth were not $(\mathrm{P}>0.05)$. In conclusion, the expression levels of miR-452-5p and miR-215-5p were significantly downregulated in colorectal cancer tissues promoting the occurrence, progression, invasion and metastasis of colorectal cancer, which suggests that miR-452-5p and miR-215-5p could be used as prognostic indicators for patients with colorectal cancer.

\section{Introduction}

Colorectal cancer is a malignant tumor originating from colon or rectal mucosal epithelium due to various factors (1), with incidence that ranks third among all malignant tumors and mortality that ranks fourth (2). There are no obvious clinical symptoms in the early stage of the disease and the diagnosis is difficult. Therefore, most patients with clinical symptoms are in the advanced stage at the time of diagnosis and metastasis of cancer cells has occurred $(3,4)$. The pathogenesis of colorectal cancer still remains unknown as there are numerous pathogenic factors, which makes the treatment of colorectal cancer more difficult (5-7). Surgical resection has been the radical treatment for colorectal cancer; however, the probability of infection after surgery is high, resulting in poor survival rate of patients $(8,9)$. Therefore, the relevant mechanisms of colorectal cancer need to be clarified and new potential therapeutic targets should be investigated to improve the prognosis of patients with colorectal cancer.

MicroRNA, a small RNA with length of 20-24 nucleotides, regulates cell endogenous functions (10). MicroRNA mainly inhibits the protein synthesis of target genes, through incomplete and complete complementation or degradation of the target genes, to regulate the biological growth and development, and to play an important regulatory role in cell proliferation, apoptosis and migration (11). It has been revealed that microRNA is a key regulator in tumor metastasis and targeted therapy (12). Upregulation of miR-452-5p inhibits stem-like traits and tumorigenesis of gliomas by inhibiting the regulatory factors of various stem cells (13). It has been reported that miR-452-5p is a tumor factor for breast malignancies, gliomas, and prostate tumors; the expression of miR-452-5p in cancerous tissues is significantly lower than that in adjacent normal tissues, and is negatively correlated with lymph node metastasis and tumor staging (14). Furthermore, miR-215-5p 
is significantly downregulated in cancerous tissues. The overexpression of miR-215-5p reduces cell proliferation, differentiation and migration, as well as the formation of cell clones. In addition, upregulation of miR-215-5p in gliomas dually inhibits tumors, effectively inhibits target genes, and reduces tumor proliferation and migration (15). However, the relationship of miR-452-5p and miR-215-5p with colorectal cancer remains unclear.

In the present study, the expression levels of miR-452-5p and miR-215-5p in colorectal cancer tissues, and their association with the clinicopathological features of colorectal cancer patients were explored, in order to provide potential targets for the treatment and prognosis of colorectal cancer.

\section{Patients and methods}

General data. A total of 50 specimens of cancerous and adjacent normal tissues were collected from colorectal cancer patients who underwent surgical resection at the Xingtai People's Hospital (Xingtai, China) from March 2012 to February 2014. The patients' clinical data were collected, including name, sex, age, tumor location, tumor diameter, tumor-node-metastasis (TNM) staging, lymph node metastasis, differentiation degree, and infiltration degree. Inclusion criteria: Patients confirmed with colorectal cancer by pathological examinations; patients who had not received any antitumor therapy (e.g., radiotherapy, chemotherapy, targeted therapy or drug therapy) before surgery; patients with complete clinical data. Exclusion criteria: Patients with familial adenomatous polyposis; patients with previous gastrointestinal diseases; patients with hypertension, diabetes, severe liver and kidney diseases, infectious diseases or other malignant tumors; and patients with mental or communication disorders. The study was approved by the Ethics Committee of Xingtai People's Hospital. All patients and their families were informed of the study and signed informed consents were obtained from the patients.

Main instruments and reagents. Roche LightCycler ${ }^{\circledR} 480 \mathrm{II}$ fluorescence PCR instrument (cat. no. 480II; Beijia Genetool Biotechnology Co., Ltd.); Ultraviolet-visible (UV-Vis) spectrophotometer Pharo 300 (cat. no. ZMK-1.00707.0001; Shanghai ZZBIO Co., Ltd.); 3\% agarose gel electrophoresis (cat. no. JKL2116; Shanghai Jingke Scientific Instrument Co., Ltd.); TRIzol ${ }^{\circledR}$ kit (cat. no. 15596-018; Beijing Solarbio Science \& Technology Co., Ltd.); TRIzol ${ }^{\circledR}$ reagent (cat. no. 15596018; Yanke Biotechnology Co., Ltd.); 5X TransScript All-in-One No-RT Control SuperMix for qPCR (cat. no. GL141-01; Beijing Transgen Biotech Co., Ltd.); 2X TransTaq HiFi PCR SuperMix II (cat. no. AS131-21; Beijing Transgen Biotech Co., Ltd.); TaqMan miRNA kit (cat. no. D1802; HaiGene). miR-452-5p, miR-215-5p and U6 internal reference primers were designed and synthesized by Beijing Dingguo Changsheng Biotechnology Co., Ltd. The required primer sequences are shown in Table I.

Experimental methods. Colorectal cancer and adjacent normal tissues were stored at $-80^{\circ} \mathrm{C}$ after being resected, and then they were cut into pieces and ground with liquid nitrogen in order to obtain the tissue suspension. Total RNA was extracted using TRIzol ${ }^{\circledR}$ reagent in strict accordance with the manufacturer's instructions. The concentration and purity of the extracted RNA were analyzed by UV-Vis spectrophotometer Pharo 300. The integrity of RNA was analyzed by $3 \%$ agarose gel electrophoresis. An A260/A280 value between 1.8 and 2.1 was considered to meet the experimental requirements. After the RNA extraction was completed, reverse transcription-quantitative polymerase chain reaction (RT-qPCR) was carried out. The reaction system was $4 \mu \mathrm{l}$ of $5 \mathrm{X}$ TransScript All-in-One No-RT Control SuperMix for PCR, $2 \mu \mathrm{g}$ of total RNA, and ribonuclease distilled water for a final volume of $20 \mu \mathrm{l}$. The reaction conditions were $25^{\circ} \mathrm{C}$ for $10 \mathrm{~min}, 42^{\circ} \mathrm{C}$ for $30 \mathrm{~min}$, $85^{\circ} \mathrm{C}$ for $5 \mathrm{sec}$; and that was the end of the inactivation of the reverse transcriptase.

After the reverse transcription reaction was completed, PCR amplification was carried out. The PCR amplification system was $2 \mu \mathrm{l}$ of cDNA, $25 \mu \mathrm{l}$ of $2 \mathrm{X}$ TransTaq HiFi PCR SuperMix II, $1 \mu \mathrm{l}$ of upstream primers, $1 \mu \mathrm{l}$ of downstream primers, and double-distilled water for a final volume of $50 \mu 1$. The PCR thermocycling conditions were as follows: Pre-denaturation at $95^{\circ} \mathrm{C}$ for $3 \mathrm{~min}$, at $94^{\circ} \mathrm{C}$ for $2 \mathrm{~min}$, at $94^{\circ} \mathrm{C}$ for $30 \mathrm{sec}$, at $55^{\circ} \mathrm{C}$ for $30 \mathrm{sec}$, at $72^{\circ} \mathrm{C} 1-2 \mathrm{~kb} / \mathrm{min}, 40$ cycles, and extension at $72^{\circ} \mathrm{C}$ for $5 \mathrm{~min}$ after completion of the cycle. The amplification data were analyzed by the Roche LightCycler ${ }^{\circledR}$ 480 II fluorescence quantitative PCR instrument. TaqMan miRNA kit was used to detect the microRNA expression levels. U6 was used as the internal reference and mRNA levels were quantified using the $2^{-\Delta \Delta \mathrm{Cq}}$ method (16).

Follow up. Patients were followed up for 5 years by telephone, letters and visits. The patients were followed up every 2 months on average until February 2019. The overall survival (OS) was calculated from the first day after surgery to the last day of follow up or the patient's date of death.

Statistical analysis. Statistical software SPSS 22.0 (IBM Corp.) was used to analyze the experimental data. Counting data were expressed as the number of cases and percentage [n (\%)]. Measurement data were expressed as the mean \pm standard deviation (SD). The comparison of measurement data between groups was conducted using paired t-test. Kaplan-Meier survival analysis was used for the generation of the survival curves of miR-452-5p and miR-215-5p highand low-expression groups, and the difference of the curves between groups was evaluated by log-rank test. Cox regression model was used to carry out univariate and multivariate analysis in order to analyze the independent factors affecting prognosis. $\mathrm{P}<0.05$ was considered to indicate a statistically significant difference.

\section{Results}

General data. Of the 50 colorectal cancer patients with complete clinical data, 32 were males and 18 were females. The patients were 27-78 years of age, including 27 patients $<53$ years of age and 23 patients $\geq 53$ years of age. The tumor diameter was $1.2-8.6 \mathrm{~cm}$ and the tumor location was in the colon ( 27 cases) and rectum ( 23 cases). There were 31 cases of good and moderate differentiation and 19 cases of poor differentiation. A total of 24 cases were in stage I+II, whereas 26 cases were in stage III+IV. There were 19 cases with lymph 
Table I. Primer sequences of miR-452-5p, miR-215-5p and U6.

\begin{tabular}{lll}
\hline Gene & \multicolumn{1}{c}{ Forward } & \multicolumn{1}{c}{ Reverse } \\
\hline miR-452-5p & 5'-GCGCAACTGTTTGCAGAG-3' & 5'-GTGCAGGGTCCGAGGT-3' \\
miR-215-5p & 5'-CTCGAGATGTCATCCTCAG-3' & 5'-GAATTCGTGAGTTCTTCTG-3' \\
U6 & 5'-CTCGCTTCGGCAGCACA-3' & 5'-AACGCTTCACGAATTTGCGT-3'
\end{tabular}

Table II. General clinical data of patients with colorectal cancer $[\mathrm{n}(\%)]$.

\begin{tabular}{lc}
\hline Clinicopathological feature & Cases \\
\hline Sex & \\
Male & $32(64.00)$ \\
Female & $18(36.00)$ \\
Age, years & \\
$<53$ & $27(54.00)$ \\
$\geq 53$ & $23(46.00)$ \\
Tumor diameter, cm & \\
$<5$ & $30(60.00)$ \\
$\geq 5$ & $20(40.00)$ \\
Tumor location & \\
Colon & $27(54.00)$ \\
Rectum & $23(46.00)$ \\
Differentiation degree & \\
Well and moderately differentiated & $31(62.00)$ \\
Poorly differentiated & $19(38.00)$ \\
TNM staging & \\
I+II & $24(48.00)$ \\
III+IV & $26(52.00)$ \\
Lymph node metastasis & \\
Yes & $19(38.00)$ \\
No & $31(62.00)$ \\
Infiltration depth & \\
T1+T2 & $29(58.00)$ \\
T3+T4 & \\
\hline
\end{tabular}

TNM, tumor-node-metastasis.

node metastasis and 31 cases without lymph node metastasis. As for infiltration depth, 21 cases were in T1+T2 stage, and 29 cases were in T3+T4 stage. Details are shown in Table II.

Expression levels of miR-452-5p and miR-215-5p in cancerous and adjacent normal tissues. The expression levels of both miR-452-5p and miR-215-5p in colorectal cancer tissues were significantly lower than those in adjacent normal tissues $(\mathrm{P}<0.05$; Table III and Fig. 1).

Relationship between miR-452-5p expression and clinicopathological features. There was no significant difference in the expression level of miR-452-5p in colorectal cancer
Table III. Expression levels of miR-452-5p and miR-215-5p in cancerous and adjacent normal tissues (mean $\pm \mathrm{SD}$ ).

\begin{tabular}{lccc}
\hline Group & $\mathrm{n}$ & $\mathrm{miR}-452-5 \mathrm{p}$ & $\mathrm{miR}-215-5 \mathrm{p}$ \\
\hline Colorectal cancer tissues & 50 & $1.15 \pm 0.21$ & $0.45 \pm 0.11$ \\
Adjacent normal tissues & 50 & $1.29 \pm 0.24$ & $0.53 \pm 0.14$ \\
$\mathrm{t}$ & - & 3.104 & 3.177 \\
P-value & - & 0.003 & 0.002 \\
\hline
\end{tabular}

patients in terms of sex, age, tumor diameter, tumor location, lymph node metastasis and infiltration depth $(\mathrm{P} \geq 0.05)$. The expression level of miR-452-5p in colorectal cancer tissues was associated with TNM staging and differentiation degree $(\mathrm{P}<0.05$; Table IV).

Relationship between miR-215-5p expression and clinicopathological features. There was no significant difference in the expression level of miR-215-5p in colorectal cancer patients in terms of sex, age, tumor diameter, tumor location and differentiation degree $(P \geq 0.05)$. The expression level of miR-215-5p in colorectal cancer tissues was associated with TNM staging, lymph node metastasis and infiltration depth $(\mathrm{P}<0.05$; Table V).

Survival of colorectal cancer patients. According to the average expression levels of miR-452-5p and miR-215-5p, the patients were classified into miR-452-5p high-expression group ( $\geq 1.15, n=33)$, miR-452-5p low-expression group $(<1.15$, $\mathrm{n}=17)$, miR-215-5p high-expression group $(\geq 0.45, \mathrm{n}=28)$ and miR-215-5p low-expression group $(<0.45, \mathrm{n}=22)$. The patients were followed up for 5 years by telephone, letters and visits. The 5-year OS rate was $78.79 \%(26 / 33)$ in the miR-452-5p high-expression group and $52.94 \%(9 / 17)$ in the miR-452-5p low-expression group. In other words, the 5-year OS rate in the miR-452-5p high-expression group was significantly higher than that in the low-expression group $(\mathrm{P}<0.05)$. The 5-year OS rates in miR-215-5p high- and low-expression groups were $53.57 \%(15 / 28)$ and $40.91 \%(9 / 22)$, respectively, indicating that the 5-year OS rate in the miR-452-5p high-expression group was significantly higher than that in the low-expression group ( $\mathrm{P}<0.05$; Fig. 2).

Univariate and multivariate analyses on prognosis of colorectal cancer. Multivariate Cox proportional hazards regression model was used to analyze the variables found in univariate analysis. The results showed that TNM staging, lymph node metastasis, miR-452-5p and miR-215-5p expres- 
Table IV. Relationship between miR-452-5p expression and clinicopathological features of colorectal cancer patients (mean \pm SD).

\begin{tabular}{|c|c|c|c|c|}
\hline Clinicopathological feature & $\mathrm{n}$ & miR-452-5p expression & $\mathrm{t}$ & P-value \\
\hline Sex & & & 0.314 & 0.755 \\
\hline Male & 32 & $1.14 \pm 0.22$ & & \\
\hline Female & 18 & $1.16 \pm 0.21$ & & \\
\hline Age, years & & & 0.488 & 0.628 \\
\hline$<53$ & 27 & $1.16 \pm 0.23$ & & \\
\hline$\geq 53$ & 23 & $1.13 \pm 0.20$ & & \\
\hline Tumor diameter, $\mathrm{cm}$ & & & 0.433 & 0.667 \\
\hline$<5$ & 30 & $1.16 \pm 0.24$ & & \\
\hline$\geq 5$ & 20 & $1.13 \pm 0.24$ & & \\
\hline Tumor location & & & 0.354 & 0.725 \\
\hline Colon & 27 & $1.16 \pm 0.19$ & & \\
\hline Rectum & 23 & $1.14 \pm 0.21$ & & \\
\hline Differentiation degree & & & 2.408 & 0.020 \\
\hline Well and moderately differentiated & 31 & $1.19 \pm 0.21$ & & \\
\hline Poorly differentiated & 19 & $1.04 \pm 0.22$ & & \\
\hline TNM staging & & & 2.132 & 0.038 \\
\hline $\mathrm{I}+\mathrm{II}$ & 24 & $1.21 \pm 0.24$ & & \\
\hline III+IV & 26 & $1.08 \pm 0.19$ & & \\
\hline Lymph node metastasis & & & 0.477 & 0.636 \\
\hline Yes & 19 & $1.13 \pm 0.24$ & & \\
\hline No & 31 & $1.16 \pm 0.20$ & & \\
\hline Infiltration depth & & & 0.326 & 0.736 \\
\hline $\mathrm{T} 1+\mathrm{T} 2$ & 21 & $1.16 \pm 0.22$ & & \\
\hline $\mathrm{T} 3+\mathrm{T} 4$ & 29 & $1.14 \pm 0.21$ & & \\
\hline
\end{tabular}

TNM, tumor-node-metastasis.
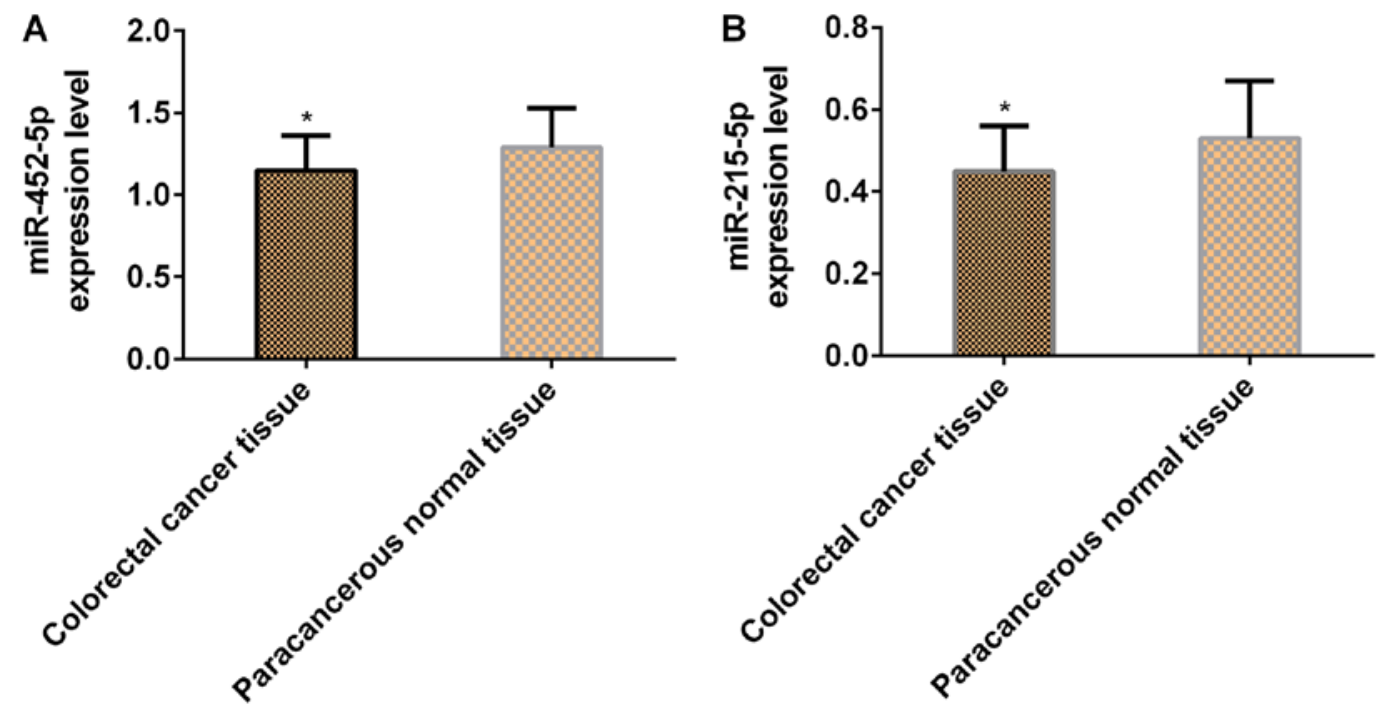

Figure 1. Expression levels of miR-452-5p and miR-215-5p in colorectal cancer and adjacent normal tissues. The results of reverse transcription-quantitative polymerase chain reaction showed that the relative expression levels of (A) miR-452-5p and (B) miR-215-5p in cancerous tissues were significantly lower than those in adjacent normal tissues. ${ }^{*} \mathrm{P}<0.05$, compared with adjacent normal tissues.

sion levels were independent risk factors affecting colorectal cancer prognosis $(\mathrm{P}<0.05)$, whereas differentiation degree and infiltration depth were not $(\mathrm{P}>0.05)$. The details of the analyses are presented in Table VI. 
Table V. Relationship between miR-215-5p expression and clinicopathological features of colorectal cancer patients (mean \pm SD).

\begin{tabular}{|c|c|c|c|c|}
\hline Clinicopathological feature & $\mathrm{n}$ & miR-215-5p expression & $\mathrm{t}$ & P-value \\
\hline Sex & & & 0.947 & 0.348 \\
\hline Male & 32 & $0.44 \pm 0.10$ & & \\
\hline Female & 18 & $0.47 \pm 0.12$ & & \\
\hline Age, years & & & 0.581 & 0.564 \\
\hline$<53$ & 27 & $0.46 \pm 0.13$ & & \\
\hline$\geq 53$ & 23 & $0.44 \pm 0.11$ & & \\
\hline Tumor diameter, $\mathrm{cm}$ & & & 0.673 & 0.504 \\
\hline$<5$ & 30 & $0.46 \pm 0.09$ & & \\
\hline$\geq 5$ & 20 & $0.44 \pm 0.12$ & & \\
\hline Tumor location & & & 1.525 & 0.134 \\
\hline Colon & 27 & $0.48 \pm 0.12$ & & \\
\hline Rectum & 23 & $0.43 \pm 0.11$ & & \\
\hline Differentiation degree & & & 1.611 & 0.114 \\
\hline Well and moderately differentiated & 31 & $0.47 \pm 0.12$ & & \\
\hline Poorly differentiated & 19 & $0.41 \pm 0.14$ & & \\
\hline TNM staging & & & 3.196 & 0.003 \\
\hline $\mathrm{I}+\mathrm{II}$ & 24 & $0.49 \pm 0.08$ & & \\
\hline III+IV & 26 & $0.38 \pm 0.15$ & & \\
\hline Lymph node metastasis & & & 2.324 & 0.024 \\
\hline Yes & 19 & $0.47 \pm 0.10$ & & \\
\hline No & 31 & $0.37 \pm 0.17$ & & \\
\hline Infiltration depth & & & 2.057 & 0.045 \\
\hline $\mathrm{T} 1+\mathrm{T} 2$ & 21 & $0.46 \pm 0.13$ & & \\
\hline $\mathrm{T} 3+\mathrm{T} 4$ & 29 & $0.39 \pm 0.11$ & & \\
\hline
\end{tabular}

TNM, tumor-node-metastasis.
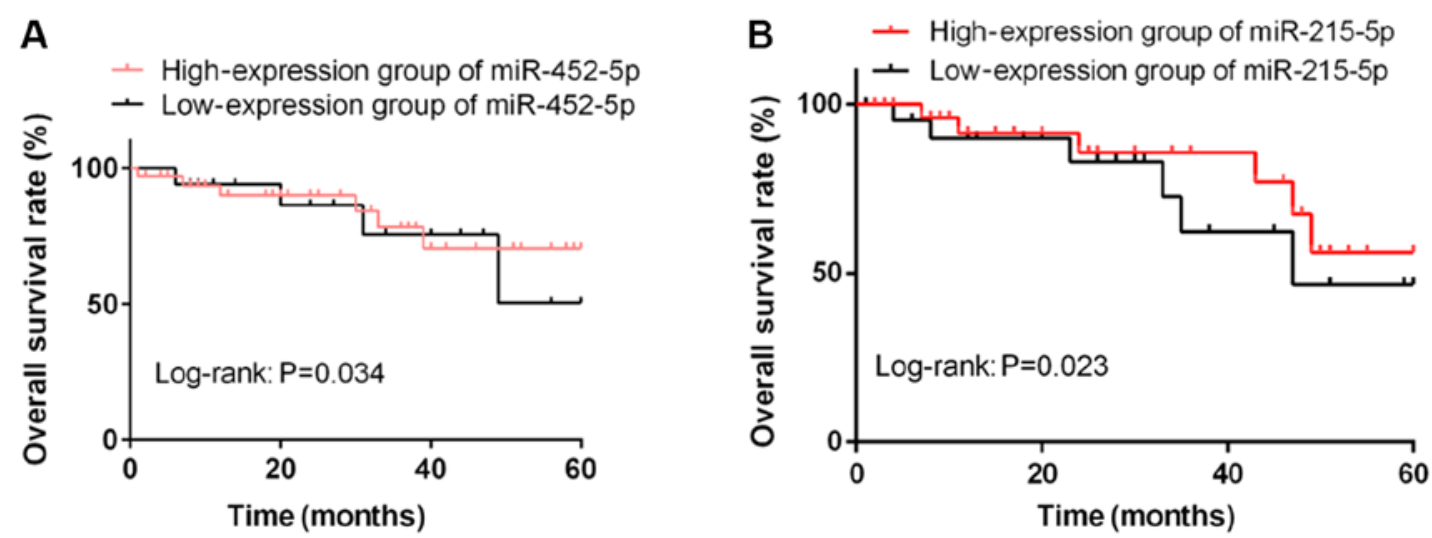

Figure 2. Relationship of miR-452-5p and miR-215-5p expression levels with OS. (A) Comparison of the 5-year OS of colorectal cancer patients between (A) the miR-452-5p high- and low-expression groups, and (B) the miR-215-5p high- and low-expression groups. OS, overall survival.

\section{Discussion}

Colorectal cancer is the second leading cause of cancer death in adults (17). In most cases, metastasis and diffusion of tumor cells are the ultimate causes of death (18). In a gradual way, normal colonic epithelial cells transform and grow benignly forming polyps, and then develop into benign adenomas, which can eventually develop into invasive cancers and lesions (19). Therefore, discovering biological indicators that affect the prognosis of colorectal cancer is of great significance for improving the prognosis of patients and increasing the survival rate.

MicroRNA is an evolutionarily endogenous, conservative and non-coding small RNA, which achieves negative regulation 
Table VI. Univariate and multivariate analysis on prognosis of colorectal cancer.

\begin{tabular}{lcccccc}
\hline & \multicolumn{3}{c}{ Univariate } & & \multicolumn{2}{c}{ Multivariate } \\
\cline { 2 - 4 } Variables & HR & $95 \%$ CI & P-value & & HR & $95 \%$ CI \\
\hline TNM staging ( I+II vs. III+IV) & 18.26 & $5.43-61.38$ & $<0.001$ & & 6.56 & $1.55-27.8$ \\
Lymph node metastasis (yes vs. no) & 3.98 & $1.71-9.30$ & 0.015 & & 3.24 & $1.32-7.96$ \\
miR-452-5p (high vs. low expression) & 3.61 & $1.85-7.09$ & 0.001 & & 4.81 & $1.98-11.7$ \\
miR-215-5p ( high vs. low expression ) & 3.01 & $1.08-8.39$ & 0.024 & 4.51 & $1.56-13.01$ \\
Infiltration depth (T1+T2 vs. T3+T4) & 4.59 & $2.13-9.89$ & & 0.111 & & - \\
Differentiation degree (well and moderately vs. poorly) & 6.46 & $2.61-15.96$ & & 0.204 & & - \\
\hline
\end{tabular}

TNM, tumor-node-metastasis; HR, hazard ratio; CI, confidence interval.

of gene expression through binding with specific target mRNA after transcription (20). MicroRNA also plays a role in tumor inhibition, cell growth induction, and inhibition of metastasis and invasion of colorectal cancer cells, and is a key regulator in cancer progression (21). miR-452-5p is related to tumor progression and has different expression in different cancers. miR-452-5p targets multiple genes and plays an important role in cancer development and occurrence through various mechanisms $(22,23)$. Furthermore, the expression of miR-215-5p in tumor tissue is significantly downregulated, which may lead to enhanced cell proliferation. A study has reported that miR-215-5p is an effective inhibitor for tumor and primary colon tumor initial cells (24). Its tumor suppression also leads to reduced proliferation, increased apoptosis and formation of new colonies (25). In the present study, the expression levels of miR-452-5p and miR-215-5p in cancerous tissues were significantly lower than those in adjacent normal tissues. In addition, the investigation of the association between the clinicopathological characteristics of colorectal cancer patients and the expression levels of miR-452-5p and miR-215-5p revealed that miR-452-5p expression was related to TNM staging and differentiation degree, whereas miR-215-5p expression was associated with TNM staging, lymph node metastasis and infiltration depth. These results indicate that miR-452-5p and miR-215-5p may be involved in the occurrence and progression of colorectal cancer. In the study by Gao et al (26), the expression of miR-452-5p was shown to be associated with TNM staging and lymph node metastasis in colorectal cancer, and miR-452-5p could target CDKNIB to stimulate tumor growth and inhibit cell apoptosis. Vychytilova-Faltejskova et al (27) reported that miR-215-5p affects specific cells; higher levels of miR-215-5p were shown to significantly reduce the metabolism and proliferation of colorectal cancer cells, as well as to inhibit cell migration, indicating the potential use of miR-215-5p in the diagnosis and prognosis of colorectal cancer. miR-452-5p and miR-215-5p may play a key role as tumor suppressor genes in colorectal cancer, and therefore, might be involved to a certain extent in the progression of colorectal cancer. Thus, miR-452-5p and miR-215-5p are both expected to be therapeutic targets and biomarkers for colorectal cancer.

In the study by $\mathrm{He}$ et al (28), the expression level of miR-452-5p was shown to be related to the survival rate of non-small cell lung cancer patients, and the highly expressed
miR-452-5p was reported to be associated with a better OS. In addition, according to the study by Halvorsen et al (29), the low expression of miR-215-5p was related to a poorer OS of patients with non-small cell lung cancer. According to the results of the present study, the 5-year OS rates in the miR-452-5p and miR-215-5p high-expression groups were significantly higher than those in the miR-452-5p and miR-215-5p low-expression groups. Cox proportional hazards model showed that miR-452-5p, miR-215-5p, TNM staging and lymph node metastasis were independent prognostic factors that may affect the survival time of colorectal cancer patients, whereas differentiation degree and infiltration depth were not. Therefore, it is believed that the degree of differentiation and the depth of invasion are prognostic factors that affect patients with colorectal cancer, although they are not independent prognostic factors. When the degree of tumor invasion increases, then the condition of the patient becomes more serious resulting in a poorer prognosis. However, the expression levels of miR-452-5p and miR-215-5p in colorectal cancer and adjacent normal tissues were not associated with sex, age, tumor diameter or tumor location, indicating that the expression levels of miR-452-5p and miR-215-5p are less susceptible to individual factors or other factors, and therefore could be used as prognostic indicators for clinical evaluation of colorectal cancer patients. miR-452-5p and miR-215-5p may play an important role in the occurrence, development and prognosis of colorectal cancer, and could be considered new biological target indices.

Although the present study confirmed the role of miR-452-5p and miR-215-5p in the occurrence, development and prognosis of colorectal cancer, there are still some limitations. Firstly, the expression levels of miR-452-5p and miR-215-5p in serum were not detected. Secondly, their effects on proliferation, apoptosis, migration and invasion of colorectal cancer cells were not further studied. These will be the aim of our future research. In addition, a greater sample size and the expression of the proteins regulated by these microRNAs will be investigated in the future.

In conclusion, the expression levels of miR-452-5p and miR-215-5p were significantly downregulated in colorectal cancer tissues, suggesting that they might promote the occurrence, progression, invasion and metastasis of colorectal cancer. Thus, miR-452-5p and miR-215-5p could be used as prognostic indicators for patients with colorectal cancer. 


\section{Acknowledgements}

Not applicable.

\section{Funding}

The study was supported by the Self-financing Project of Xingtai Municipal Science and Technology Plan (no. 2017ZC119).

\section{Availability of data and materials}

The datasets used and/or analyzed during the present study are available from the corresponding author on reasonable request.

\section{Authors' contributions}

JY analyzed and interpreted the patient general data. HL performed PCR. YD and JW were responsible for the statistical analysis of the data. RW was responsible for the follow-up of the patients. JY wrote the manuscript. All authors read and approved the final version of the manuscript.

\section{Ethics approval and consent to participate}

The study was approved by the Ethics Committee of Xingtai People's Hospital. Patients who participated in this research had complete clinical data and provided a signed informed consent.

\section{Patient consent for publication}

Not applicable.

\section{Competing interests}

The authors declare that they have no competing interests.

\section{References}

1. Al Dahhan SA and Al Lami FH: Epidemiology of Colorectal Cancer in Iraq, 2002-2014. Gulf J Oncolog 1: 23-26, 2018.

2. Abdulla MH, Valli-Mohammed MA, Al-Khayal K, Al Shkieh A, Zubaidi A, Ahmad R, Al-Saleh K, Al-Obeed O and McKerrow J: Cathepsin B expression in colorectal cancer in a Middle East population: Potential value as a tumor biomarker for late disease stages. Oncol Rep 37: 3175-3180, 2017.

3. Vatandoust S, Price TJ and Karapetis CS: Colorectal cancer: Metastases to a single organ. World J Gastroenterol 21: 11767-11776, 2015.

4. Arnold M, Sierra MS, Laversanne M, Soerjomataram I, Jemal A and Bray F: Global patterns and trends in colorectal cancer incidence and mortality. Gut 66: 683-691, 2017.

5. Li CX, An XX, Zhao B, Wu SJ, Xie GH and Fang XM: Impact of operation timing on post-operative infections following colorectal cancer surgery. ANZ J Surg 86: 294-298, 2016.

6. Katsidzira L, Gangaidzo I, Thomson S, Rusakaniko S, Matenga J and Ramesar R: The shifting epidemiology of colorectal cancer in sub-Saharan Africa. Lancet Gastroenterol Hepatol 2: 377-383, 2017.

7. Legrand N,Dixon DA and SobolewskiC: AU-rich element-binding proteins in colorectal cancer. World J Gastrointest Oncol 11: 71-90, 2019.

8. Govaert JA, van Dijk WA, Fiocco M, Scheffer AC, Gietelink L, Wouters MW and Tollenaar RA: Nationwide outcomes measurement in colorectal cancer surgery: Improving quality and reducing costs. J Am Coll Surg 222: 19-29.e2, 2016.
9. Curtis NJ, Taylor M, Fraser L, Salib E, Noble E, Hipkiss R, Allison AS, Dalton R, Ockrim JB and Francis NK: Can the combination of laparoscopy and enhanced recovery improve long-term survival after elective colorectal cancer surgery? Int J Colorectal Dis 33: 231-234, 2018.

10. Obad S, dos Santos CO, Petri A, Heidenblad M, Broom O, Ruse C Fu C, Lindow M, Stenvang J, Straarup EM, et al: Silencing of microRNA families by seed-targeting tiny LNAs. Nat Genet 43: 371-378, 2011.

11. Bhome R, Del Vecchio F, Lee G-H, Bullock MD, Primrose JN, Sayan AE and Mirnezami AH: Exosomal microRNAs (exomiRs): Small molecules with a big role in cancer. Cancer Lett 420: 228-235, 2018.

12. Zhai W, Li S, Zhang J, Chen Y, Ma J, Kong W, Gong D, Zheng J, Xue W and Xu Y: Sunitinib-suppressed miR-452-5p facilitates renal cancer cell invasion and metastasis through modulating SMAD4/SMAD7 signals. Mol Cancer 17: 157, 2018.

13. Liu L, Chen K, Wu J, Shi L, Hu B, Cheng S, Li M and Song L: Downregulation of miR-452 promotes stem-like traits and tumorigenicity of gliomas. Clin Cancer Res 19: 3429-3438, 2013

14. He Z, Xia Y, Pan C, Ma T, Liu B, Wang J, Chen L and Chen Y: Up-regulation of MiR-452 inhibits metastasis of non-small cell lung cancer by regulating BMI1. Cell Physiol Biochem 37: 387-398, 2015.

15. Wang C, Chen Q, Li S, Li S, Zhao Z, Gao H, Wang X, Li B, Zhang W, Yuan Y, et al: Dual inhibition of PCDH9 expression by miR-215-5p up-regulation in gliomas. Oncotarget 8 : 10287-10297, 2017.

16. Livak KJ and Schmittgen TD: Analysis of relative gene expression data using real-time quantitative PCR and the 2(-Delta Delta C(T)) method. Methods 25: 402-408, 2001.

17. Simon K: Colorectal cancer development and advances in screening. Clin Interv Aging 11: 967-976, 2016.

18. Ling H, Pickard K, Ivan C, Isella C, Ikuo M, Mitter R, Spizzo R, Bullock M, Braicu C, Pileczki V, et al: The clinical and biological significance of MIR-224 expression in colorectal cancer metastasis. Gut 65: 977-989, 2016.

19. Yang S, Sun Z, Zhou Q, Wang W, Wang G, Song J, Li Z, Zhang Z, Chang Y, Xia K, et al: MicroRNAs, long noncoding RNAs, and circular RNAs: Potential tumor biomarkers and targets for colorectal cancer. Cancer Manag Res 10: 2249-2257, 2018.

20. Wolter JM, Le HH, Linse A, Godlove VA, Nguyen TD, Kotagama K, Lynch A, Rawls A and Mangone M: Evolutionary patterns of metazoan microRNAs reveal targeting principles in the let-7 and miR-10 families. Genome Res 27: 53-63, 2017.

21. Wei W, Yang Y, Cai J, Cui K, Li RX, Wang H, Shang X and Wei D: miR-30a-5p suppresses tumor metastasis of human colorectal cancer by targeting ITGB3. Cell Physiol Biochem 39: 1165-1176, 2016

22. Gan XN, Gan TQ, He RQ, Luo J, Tang RX, Wang HL, Zhou H, Qing $\mathrm{H}, \mathrm{Ma} \mathrm{J}, \mathrm{Hu} \mathrm{XH}$, et al: Clinical significance of high expression of miR-452-5p in lung squamous cell carcinoma. Oncol Lett 15: 6418-6430, 2018.

23. Kolligs FT: Diagnostics and Epidemiology of Colorectal Cancer. Visc Med 32: 158-164, 2016.

24. Ullmann P, Nurmik M, Schmitz M, Rodriguez F, Weiler J, Qureshi-Baig K, Felten P, Nazarov PV, Nicot N, Zuegel N, et al: Tumor suppressor miR-215 counteracts hypoxia-induced colon cancer stem cell activity. Cancer Lett 450: 32-41, 2019.

25. Bouvier AM and Launoy G: Epidemiology of colorectal cancer. Rev Prat 65: 767-773, 2015 (In French).

26. Gao L, Gan XN, Ye ZH, et al: MiR-452-5p may serve as an oncogene in colorectal cancer through targeting CDKN1B: A study based on bioinformatics analysis and dual-luciferase reporter assay. Int J Clin Exp Med 12: 2151-2166, 2019.

27. Vychytilova-Faltejskova P, Merhautova J, Machackova T, Gutierrez-Garcia I, Garcia-Solano J, Radova L, Brchnelova D, Slaba K, Svoboda M, Halamkova J, et al: MiR-215-5p is a tumor suppressor in colorectal cancer targeting EGFR ligand epiregulin and its transcriptional inducer HOXB9. Oncogenesis 6: 399, 2017.

28. He Z, Xia Y, Liu B, Qi X, Li Z, Wang J, Chen L and Chen Y: Down-regulation of miR-452 is associated with poor prognosis in the non-small-cell lung cancer. J Thorac Dis 8: 894-900, 2016.

29. Halvorsen AR, Sandhu V, Sprauten M, Flote VG, Kure EH, Brustugun OT and Helland A: Circulating microRNAs associated with prolonged overall survival in lung cancer patients treated with nivolumab. Acta Oncol 57: 1225-1231, 2018.

This work is licensed under a Creative Commons Attribution-NonCommercial-NoDerivatives 4.0 International (CC BY-NC-ND 4.0) License. 